\title{
Evidence of Two Ciliated Epithelial Cell Subsets in Mouse Airways
}

\author{
Xin Sun ${ }^{1,2 \#}$, Ruo Chi ${ }^{1,2 \#}$, Junping Wu ${ }^{1,2}$, Xue $\mathrm{Li}^{1,2}$, Li Li ${ }^{1,2}$, Long $\mathrm{Xu}^{1,2}$, Chenghu Liu ${ }^{3}$, Jing Feng ${ }^{4}$, Qi Wu $\mathbf{u}^{1,2^{*}}$ and Huaiyong Chen ${ }^{1,2^{\star}}$ \\ ${ }^{1}$ Tianjin Haihe Hospital, Tianjin, 300350, China \\ ${ }^{2}$ Tianjin Institute of Respiratory Diseases, Tianjin 300350, China \\ ${ }^{3}$ Department of Immunology, Nankai University School of Medicine, Tianjin 300071, China \\ ${ }^{4}$ Department of Respiratory, Tianjin Medical University General Hospital, Tianjin 300052, China \\ \#Contributed to the work equally
}

*Corresponding author: Huaiyong C, Tianjin Haihe Hospital, Tianjin Institute of Respiratory Diseases, Tianjin 300350, China, Tel: 86-22-58830336; E-mail: huaiyong.chen@foxmail.com

Qi W, Tianjin Haihe Hospital, Tianjin Institute of Respiratory Diseases, Tianjin 300350, China, Tel: 86-22-58830042; E-mail: wq572004@163.com

Rec date: Mar 13, 2014, Acc date: Apr 20, 2014, Pub date: Apr 22, 2014

Copyright: ( 2014 Huaiyong $C$, et al. This is an open-access article distributed under the terms of the Creative Commons Attribution License, which permits unrestricted use, distribution, and reproduction in any medium, provided the original author and source are credited.

\begin{abstract}
Patients with asthma-associated airway epithelial damage exhale increased levels of nitric oxide (NO). However, the distribution of endothelial NO synthase (eNOS) in mouse airways remains to be controversial. In the present study, mouse lung sections were stained using antibodies against secretoglobin 1A member [1] (Scgb1a1), acetylated tubulin (ACT), and eNOS. We found that club cells in the mouse airways are immunoreactive toward eNOS. In addition, to the best of our knowledge, for the first time, two subsets of ciliated cells that differ in their expression of eNOS were observed to reside in the mouse airways. Both subsets of ciliated cells survived naphthalene-induced lung injury. These data will help clarify a controversial issue of whether ciliated cells contribute to epithelial maintenance in the airways.
\end{abstract}

Keywords: Mouse airway; Ciliated cells; eNOS; Scgbla1; Naphthalene

\section{Introduction}

Nitric oxide (NO), an important messenger molecule in cells, is formed endogenously in the airways of the lung. NO generated by various isoforms of NO synthase (NOS) plays crucial and diverse physiological roles and has been implicated in several diseases including asthma and chronic obstructive pulmonary disease [1]. Endothelial NOS (eNOS), originally identified in the endothelium of vascular tissue, is responsible for the majority of the NO produced in this tissue [2]. NO that is produced by eNOS acts as a bronchial vasodilator [3]. In addition to its expression in vasculature tissues, eNOS has been found in the epithelia of airways and is important for their functions. For example, eNOS localizes to the basal membrane of ciliary microtubules in rat lungs and stimulates ciliary beat frequency, which determines the functions of the ciliated cells $[4,5]$. However, it remains controversial whether ciliated cells contribute to epithelial regeneration in the airways.

Ciliated cells are a terminally differentiated population that is replenished by club cells and/or stem cells residing in the airway epithelia under steady state or during lung injuries [6,7]. Several studies have shown that ciliated cells are capable of giving rise to goblet cells under certain conditions. For example, the epidermal growth factor receptor is activated in ciliated cells during Sendai virus infection, leading to the expression of goblet cell markers in these cells [8]. Turner and colleagues have provided evidence that human ciliated cells convert to goblet cells in culture [9]. In these studies, ciliated cells are characterized by only a few markers including acetylated tubulin (ACT) and Forkhead box protein J1 (FoxJ1). Thus, two or more functionally distinct ciliated cells possibly exist in the airway epithelia, and they cannot be distinguished using the ACT or FoxJ1 markers. In this study, we present preliminary immunofluorescent staining evidence showing that the ciliated cells of the mouse airway include two subsets that are distinguished by their expression of eNOS. These data help clarify the contribution of ciliated cells to epithelial maintenance in airways.

\section{Materials and Methods}

\section{Animals}

C57BL/6 mice were maintained in pathogen-free conditions in the Tianjin animal facility. Mice were exposed to a 12-h light/dark cycle and had free access to food and water. Adult mice between the ages of 2 and 4 months were sacrificed for experiments according to a protocol approved by the Nankai University Animal Care and Use Committee.

\section{Reagents}

Naphthalene, mouse IgG2b anti-ACT $(1: 8,000)$ antibody, and goat polyclonal anti-Scgblal antibody (1:50) were purchased from SigmaAldrich (St. Louis, MO, USA). Mouse monoclonal IgG1 anti-eNOS (1:500) was purchased from Santa Cruz Biotechnology (Dallas, TX, USA).

\section{Naphthalene Administration}

Naphthalene was dissolved in Mazola corn oil and injected intraperitoneally at a dose of $275 \mathrm{mg} / \mathrm{kg}$. All the injections were performed between 8:00 and 10:00 a.m. to normalize injury responses. 
Untreated animals were used as controls. At the day post-naphthalene injection indicated, the mice were sacrificed for analysis.

\section{Immunofluorescence Staining}

Lung lobes were processed for histological analysis by using standard methods described previously [10]. Briefly, lung tissues were fixed by instillation of $10 \%$ neutral buffered formalin, followed by immersion in $10 \%$ neutral buffered formalin for a total of $2 \mathrm{~h}$ at $4^{\circ} \mathrm{C}$. Five-micrometer sections were collected from the lung tissues. Sections were incubated with primary antibodies at $4^{\circ} \mathrm{C}$ overnight, washed with phosphate-buffered saline, and then incubated with the appropriate fluorochrome-conjugated secondary antibody for $2 \mathrm{~h}$ at room temperature. Slides were mounted in Fluoromount $\mathrm{G}$ containing 4',6-diamidino-2-phenylindole (DAPI). Staining was visualized using a Zeiss Axiovert 40 inverted fluorescent microscope.

\section{Results}

\section{Expression of eNOS in mouse airway epithelia}

To assay eNOS expression in mouse airways, immunofluorescence staining was performed on lung tissue sections. Immunoreactivities of Scgblal and eNOS indicated that they colocalized in the proximal airway, suggesting that eNOS is expressed in mouse club cells (Figure $1 \mathrm{~A}-\mathrm{C}$ ). Club cells negative for eNOS were not observed in the present study. Consistent with the previous reports [4,11], the immunoreactivities of eNOS and the ciliated cell marker ACT revealed that ciliated cells in the proximal airway expressed eNOS (Figure $1 \mathrm{D}-$ F). We also observed for the first time that the proximal airway epithelium in the mouse contained a subset of ciliated cells that did not express eNOS (Figure $1 \mathrm{D}-\mathrm{F})$. These eNOS-negative ciliated cells were also observed in the distal airway epithelium (Figure $1 \mathrm{G}-\mathrm{J}$ ). Analysis of [3-5] individual lung sections indicated that eNOSpositive ciliated cells were more abundant than eNOS-negative ciliated cells in both the proximal and the distal airways of mouse (Figure 1K).

\section{eNOS-negative ciliated cells resist naphthalene-induced lung injury}

Ciliated cells that express eNOS have been shown to resist naphthalene-induced lung injury [12]. Therefore, we examined whether eNOS-negative ciliated cells had a similar capacity. To address this, naphthalene was injected intraperitoneally into mice. As reported previously [13], most Scgbla1-expressing club cells were ablated 1 day post-naphthalene (Figure 2A), except for a few Scgblal-expressing cells residing in the distal airway that survived the naphthaleneinduced injury. These surviving Scgbla1-expressing cells were immunoreactive for eNOS (Figure 2B). Moreover, we observed that both eNOS-positive (Figure 2C-D) and eNOS-negative ciliated cells (Figure 2C-D) survived naphthalene injury. By day 10, during the post-injection repair process, a significant number of Scgbla1expressing cells were regenerated in the airway epithelium (Figure $2 \mathrm{~F}$ I). During the injury process (day 1 post-naphthalene), greater than $70 \%$ of the surviving ciliated cells in both the proximal and distal airways were negative for eNOS (Figure 2J). However, during the repair process (day 10 post-naphthalene), the relative abundance of eNOS-positive ciliated cells in the total ciliated cell population returned back to normal levels in both the proximal and the distal airways (Figure 2K).

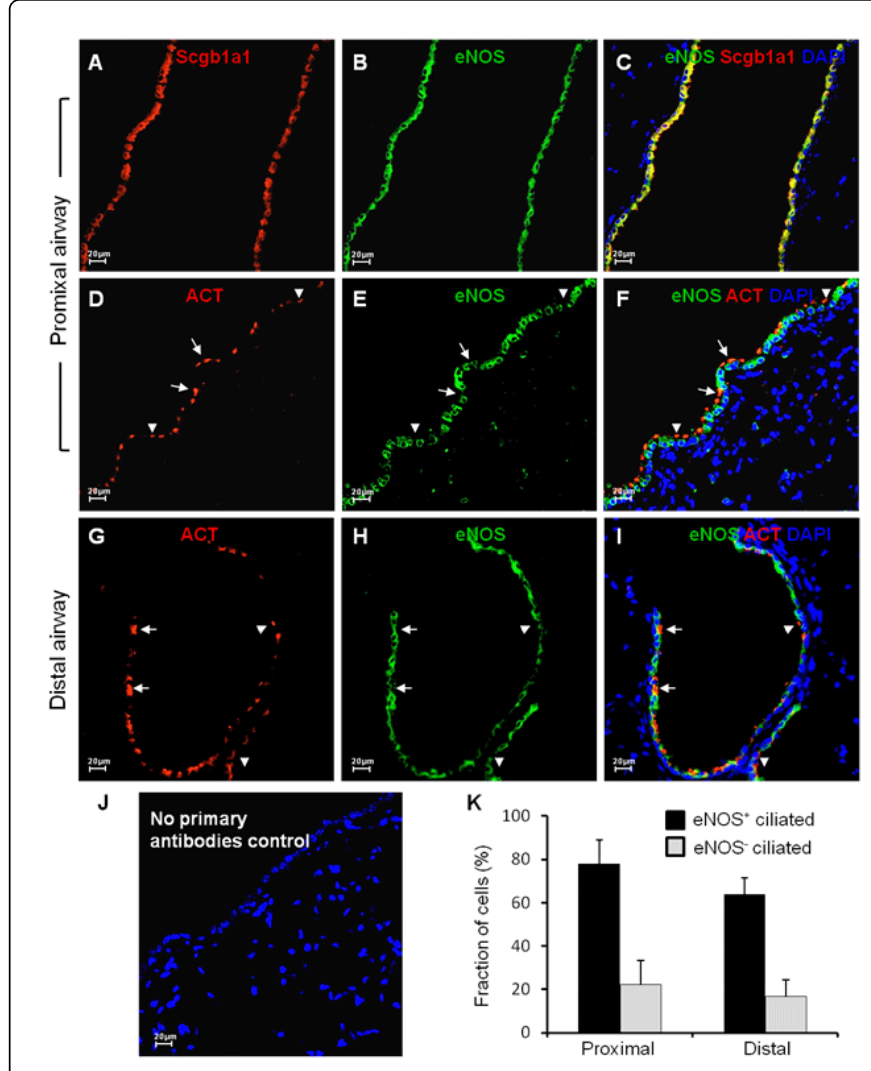

Figure 1: Expression of eNOS in mouse airway epithelial cells. Lung sections from C57BL/6 mice were stained using antibodies for the epithelial club cell marker secretoglobin $1 \mathrm{~A}$ member 1 (Scgbla1) (A), endothelial nitric oxide synthase (eNOS) (B, E, H), or airway ciliated cell marker acetylated tubulin (ACT) $(D, G)$, followed by fluorochrome-conjugated secondary antibody. 4',6-Diamidino-2phenylindole (DAPI) was included in the mounting medium to mark the cell nuclei (blue). Merged images are shown in C, F and I. Negative control without Scgblal and ACT antibodies but with secondary fluorescent antibodies and DAPI was included (J). Arrows indicate ciliated cells stained with eNOS, while arrowheads mark ciliated cells lacking eNOS expression. Images shown are representative of five individual mice. The proportions of eNOS+ and eNOS- ciliated cells analyzed in 3-5 individual images of the proximal or distal airways are summarized in $\mathrm{K}$.

Further, more alveolar cells exhibited immunoreactivity for eNOS in the naphthalene-injected group compared to the controls, suggesting that the expression of eNOS can be induced by naphthalene injury. 


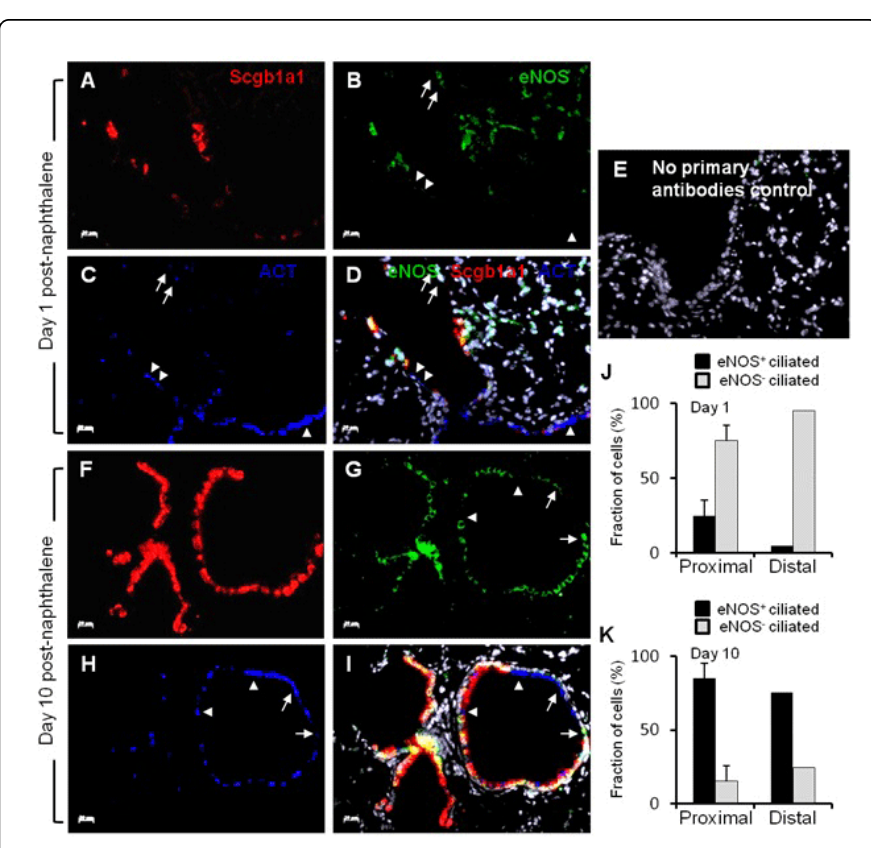

Figure 2: Both subsets of ciliated cells survive naphthalene injury. C57BL/6 mice were intraperitoneally injected with naphthalene and were then sacrificed on days 1 and 10 post injection. Lungs were collected and processed for Scgblal (A and F), eNOS (B and G), and $\mathrm{ACT}(\mathrm{C}$ and $\mathrm{H})$ staining. Merged images are shown in $\mathrm{D}$ and $\mathrm{I}$. Nuclei were visualized using DAPI (white). Negative control without Scgbla1 and ACT antibodies but with secondary fluorescent antibodies and DAPI was included (E). Data are representative of four individual mice. Proportions of eNOS+ and eNOS- ciliated cells were analyzed in 3-5 individual images of the proximal and distal airways from mice collected from day 1 postnaphthalene (J) and day 10 post-naphthalene (K).

\section{Discussion}

The airway epithelium plays critical roles as a protective physical and functional barrier between the external environment and underlying tissues, and as a central element in the initiation and regulation of immune responses in the lung [14]. Epithelial repair is initiated quickly after injury by club cells, which act as endogenous progenitors [15]. During the airway reparative process, club cells exhibit differential potential to become ciliated and mucous cells $[16,17]$. Hierarchically, club cells are replenished in the distal airway by a naphthalene-resistant epithelial stem cell population that has been characterized recently [18]. Club cells are known to express eNOS [19]; however, Konig and colleagues found that club cells are not immunoreactive for eNOS in rat lungs [20]. This discrepancy might be attributed to the source of the eNOS antibodies used in the different studies. Our data clarify this issue by showing that eNOS clearly colocalized with Scgb1a1, a marker of epithelial club cells.

A large body of evidence indicates that structural and functional epithelial alterations play critical roles in both the development and persistence of asthmatic inflammation [21]. During this pathological process, the airway epithelium of asthmatic patients appears to be altered and unable to repair itself. NO is an important messenger in cells and increased levels of exhaled NO are detected in patients with bronchial asthma $[\mathbf{2 2}, 23]$. Incomplete repair of the airway epithelium in asthmatic patients suggests epithelial regeneration may be negatively regulated by NO. Studies performed using an ovalbumininduced murine asthma model showed that a $75 \%$ decrease in club cells and a $25 \%$ decrease in ciliated cells are accompanied by a marked increase in mucin-producing goblet cells [24].

Cilia are an important instrument of mucociliary clearance [25]. NO stimulates ciliary beat frequency and, therefore, is beneficial to airway mucociliary clearance [26]. Loss of ciliated cells contributes to the reduced ability of mucociliary clearance in asthma. Ciliated cells have also been proposed to serve as progenitors of goblet cells. In vitro culture of human ciliated cells that express enhanced green fluorescent protein (eGFP) in the presence of the asthmatic cytokine interleukin [13] leads to the eGFP labeling of goblet cells, suggesting that ciliated cells have the potential to give rise to goblet cells [9]. However, recently reported data indicated that this is not the case in mouse airways. Genetic labeling of ciliated cells with enhanced yellow fluorescent protein indicated that ciliated cells proliferate but do not give rise to goblet cells in the ovalbumin-induced murine model of allergic lung disease [27]. In the current study, we observed for the first time that the two subsets of ciliated cells exist in mouse airways that show differential expression of eNOS. One subset expresses eNOS, but the other one does not. Both subtypes survived naphthalene-induced lung injury. We were unable to distinguish their functions in the current study, but our data raise a number of interesting questions regarding the potential roles of the ciliated cells in airway maintenance and repair. For example, it is not clear whether one subtype of ciliated cells give rise goblet cells under asthmatic conditions. Therefore, future efforts to isolate these two cell subtypes and to identify their functions in steady state and reparative processes after lung injuries are crucial to address these questions.

\section{Acknowledgements}

This work was supported by the Natural Science Foundation of Tianjin City (Nos. 13JCYBJC40000, 13JCYBJC22400).

\section{References}

1. Ricciardolo FL, Sterk PJ, Gaston B, Folkerts G (2004) Nitric oxide in health and disease of the respiratory system. Physiol Rev 84: 731-765.

2. Förstermann U, Münzel T (2006) Endothelial nitric oxide synthase in vascular disease: from marvel to menace. Circulation 113: 1708-1714.

3. Feletou M, Lonchampt M, Coge F, Galizzi JP, Bassoullet C, et al. (2001) Regulation of murine airway responsiveness by endothelial nitric oxide synthase. Am J Physiol Lung Cell MolPhysiol 281: L258-267.

4. Zhan X, Li D, Johns RA (2003) Expression of endothelial nitric oxide synthase in ciliated epithelia of rats. J HistochemCytochem 51: 81-87.

5. Krasteva G, Pfeil U, Filip AM, Lips KS, Kummer W, et al. (2007) Caveolin-3 and eNOScolocalize and interact in ciliated airway epithelial cells in the rat. Int J Biochem Cell Biol 39: 615-625.

6. Reynolds SD, Giangreco A, Power JH, Stripp BR (2000) Neuroepithelial bodies of pulmonary airways serve as a reservoir of progenitor cells capable of epithelial regeneration. Am J Pathol 156: 269-278.

7. Giangreco A, Reynolds SD, Stripp BR (2002) Terminal bronchioles harbor a unique airway stem cell population that localizes to the bronchoalveolar duct junction. Am J Pathol 161: 173-182.

8. Tyner JW, Kim EY, Ide K, Pelletier MR, Roswit WT, et al. (2006) Blocking airway mucous cell metaplasia by inhibiting EGFR antiapoptosis and IL-13 transdifferentiation signals. J Clin Invest 116: 309-321. 
Citation: $\quad$ Xin S, Ruo C, Junping W, Xue L, Li L, et al. (2014) Evidence of Two Ciliated Epithelial Cell Subsets in Mouse Airways. Bioenergetics 3:

Page 4 of 4

9. Van Winkle LS, Isaac JM, Plopper CG (1997) Distribution of epidermal growth factor receptor and ligands during bronchiolar epithelial repair from naphthalene-induced Clara cell injury in the mouse. Am J Pathol 151: 443-459.

10. Turner J, Roger J, Fitau J, Combe D, Giddings J, et al. (2011) Goblet cells are derived from a FOXJ1-expressing progenitor in a human airway epithelium. Am J Respir Cell MolBiol 44: 276-284.

11. Reynolds SD, Zemke AC, Giangreco A, Brockway BL, Teisanu RM, et al. (2008) Conditional stabilization of beta-catenin expands the pool of lung stem cells. Stem Cells 26: 1337-1346.

12. Xue C, Botkin SJ, Johns RA (1996) Localization of endothelial NOS at the basal microtubule membrane in ciliated epithelium of rat lung. J HistochemCytochem 44: 463-471.

13. Reynolds SD, Hong KU, Giangreco A, Mango GW, Guron C, et al. (2000) Conditional clara cell ablation reveals a self-renewing progenitor function of pulmonary neuroendocrine cells. Am J Physiol Lung Cell MolPhysiol 278: 1256-1263.

14. Stripp BR, Reynolds SD (2008) Maintenance and repair of the bronchiolar epithelium. Proc Am ThoracSoc 5: 328-333.

15. Vareille M, Kieninger E, Edwards MR, Regamey N (2011) The airway epithelium: soldier in the fight against respiratory viruses. ClinMicrobiol Rev 24: 210-229.

16. Tsao PN, Wei SC, Wu MF, Huang MT, Lin HY, et al. (2011) Notch signaling prevents mucous metaplasia in mouse conducting airways during postnatal development. Development 138: 3533-3543.

17. Rawlins EL, Okubo T, Xue Y, Brass DM, Auten RL, et al. (2009) The role of Scgbla1+ Clara cells in the long-term maintenance and repair of lung airway, but not alveolar, epithelium. Cell Stem Cell 4: 525-534.

18. Chen H, Matsumoto K, Brockway BL, Rackley CR, Liang J, et al. (2012) Airway epithelial progenitors are region specific and show differential responses to bleomycin-induced lung injury. Stem Cells 30: 1948-1960.
19. Zhan X, Li D, Johns RA (1999) Immunohistochemical evidence for the NO cGMP signaling pathway in respiratory ciliated epithelia of rat. J HistochemCytochem 47: 1369-1374.

20. König P, Dedio J, Oess S, Papadakis T, Fischer A, et al. (2005) NOSIP and its interacting protein, eNOS, in the rat trachea and lung. J HistochemCytochem 53: 155-164.

21. Cardinale F, Giordano P, Chinellato I, Tesse R (2013) Respiratory epithelial imbalances in asthma pathophysiology. Allergy Asthma Proc 34: 143-149.

22. Lehtimäki L, Turjanmaa V, Kankaanranta H, Saarelainen S, Hahtola P, et al. (2000) Increased bronchial nitric oxide production in patients with asthma measured with a novel method of different exhalation flow rates. Ann Med 32: 417-423.

23. Yates DH (2001) Role of exhaled nitric oxide in asthma. Immunol Cell Biol 79: 178-190.

24. Reader JR, Tepper JS, Schelegle ES, Aldrich MC, Putney LF, et al. (2003) Pathogenesis of mucous cell metaplasia in a murine asthma model. Am J Pathol 162: 2069-2078.

25. Stannard W, O'Callaghan C (2006) Ciliary function and the role of cilia in clearance. J Aerosol Med 19: 110-115.

26. Yang B, Schlosser RJ, McCaffrey TV (1996) Dual signal transduction mechanisms modulate ciliary beat frequency in upper airway epithelium. Am J Physiol 270: L745-751.

27. Pardo-Saganta A, Law BM, Gonzalez-Celeiro M, Vinarsky V, Rajagopal J (2013) Ciliated cells of pseudostratified airway epithelium do not become mucous cells after ovalbumin challenge. Am J Respir Cell MolBiol 48: 364-373. 